www.jmscr.igmpublication.org

Impact Factor 5.84

Index Copernicus Value: 83.27

ISSN (e)-2347-176x ISSN (p) 2455-0450

crossref DOI: _https://dx.doi.org/10.18535/jmscr/v5i4.08

Journal Of Medical Science And Clinical Research

IGM Publication

An Official Publication of IGM Publication

\title{
A Comparative Study on the Effect of Yoga and Strengthening Exercises on the Symptoms of Fibromyalgia in Women
}

\author{
Authors \\ Jeba Chitra $^{1}$, Anneri Chheda ${ }^{2}$, Ankita Dessai $^{3}$ \\ ${ }^{1}$ Master Degree Holder, Professor, Department of Neurophysiotherapy, KLE University's Institute of \\ Physiotherapy, Belagavi Contact info- 09886510290 \\ ${ }^{2}$ Bachelor Degree Holder, Physiotherapist, Department of Physiotherapy, KLE University's Institute of \\ Physiotherapy. Contact info- 07829638525 \\ ${ }^{3}$ Bachelor Degree Holder, Physiotherapist, Department of Physiotherapy, KLE University's Institute of \\ Physiotherapy. Contact info- 08748051716
}

\begin{abstract}
Fibromyalgia (FM) is condition characterised by wide spread pain, fatigue and sleep irregularities. It is more common in women than men. A number of pharmacological and non pharmacological treatments have been noted by researchers and efficacy of physiotherapy to relieve symptoms of Fibromyalgia has also been established previously. However, there is scope to identify an effective treatment for the same employing both conventional and contemporary modalities of therapy like strengthening exercises and yoga. Thus the objective of the study was to compare the effect of yoga and strengthening exercises on the symptoms of fibromyalgia in women. Data collection was done from educational institutions in Belagavi, India. Women between the age group of 18-45 years were screened using the Revised Fibromyalgia Criteria and were recruited for the study. Informed consent, demographic data and scores of Revised Fibromyalgia Impact Questionnaire were obtained and documented. Subjects were randomly assigned into two groups using envelope method. One group was given Yoga and other group was given strengthening exercises for 7 days. Post intervention data were obtained and analysed. There was statistical significance in both groups with yoga showing greater effect than strengthening exercises in the improvement of symptoms of fibromyalgia. This study concludes that yoga had better effect than strengthening exercises on the symptoms of fibromyalgia in women and must be practised by subjects with FM to reduce the symptoms as much as possible.

Keywords- Fibromyalgia, Yoga, strengthening exercise, physiotherapy.
\end{abstract}

\section{INTRODUCTION}

Fibromyalgia (FM) is a condition characterized by widespread musculoskeletal pain along with symptoms like tenderness, fatigue, sleep disturbance, cognition problems and psychoogical distress. ${ }^{1}$ A prevalence of $2-7 \%$ has been noted in different countries, with an average female to male ratio of $9: 1{ }^{1}$ The peak of symptoms being noted in the childbearing age of women i.e. $18-45$ years. $^{2}$

The exact aetiology of Fibromyalgia is still not known, although various studies suggest involvement of both genetic susceptibility as well as environmental trigger factors. ${ }^{3}$ Evidence 
suggests presence of a gene signature in the individuals with $\mathrm{FM}^{3}$ while few other studies suggest there might be altered hypothalamic pituitary adrenal axis, abnormal processing of pain in central nervous system, and/or autonomic nervous dysfunction related to reduced levels of serotonin, nor epinephrine, and dopamine. $^{4,5,6}$ Other than this, triggering events that include persistent focal pain disorders, childhood abuse, injuries, depression, hypermobility, infection with hepatitis C,Sjögren's syndrome, systemic lupus erythematosus, HIV, early-onset migraine and post-traumatic stress disorder have been noted. ${ }^{3}$ The diagnosis of this condition is mainly based on the Fibromyalgia Diagnostic Criteria (FDC) proposed by the American College of Rheumatology (ACR) in $1990,{ }^{7}$ which has been revised in $2010,{ }^{8} 2011^{9}$ and then in 2016. ${ }^{10}$

There is no definite cure for FM, though current treatment options offer symptomatic management through both pharmacological and non-pharmacological therapies. ${ }^{11}$ The nonpharmacological treatments proposed are acupuncture, biofeedback, capsaicin, chiropractic, cognitive behavioural therapies, exercise, hydrotherapy, spa therapy, hypnotherapy, massage, meditative movement (Quigong, yoga, tai chi), mindfulness/mind-body therapy, multicomponent therapy, S-adenosyl methionine and other complementary and alternative therapies. ${ }^{11}$ Modern medicine like physical therapy aides with modalities like stretching, strengthening, aerobic training and endurance training to provide symptomatic relief for these subjects. ${ }^{12,13}$ Of these, strengthening provides greater results in reducing symptoms like pain in subjects with fibromyalgia. ${ }^{14}$ In a study conducted by J. Derek Kingsley et al, found that strengthening led to improvement of pain along with improvement in independence and quality of life in subjects with FM. ${ }^{15}$

Alternate therapies like yoga focus on body, mind and breathing of an individual through practice of breathing techniques (pranayamas), physical poses (asanas) and meditation (dhyaana). ${ }^{16}$ Carson et al conducted a randomised clinical trial and found that Yoga had promising results in the symptoms of FM including pain, fatigue, emotional disturbances and other coping strategies. ${ }^{17}$

This study was undertaken to compare the effect of yoga and strengthening exercises on the symptoms of fibromyalgia in women.

\section{MATERIALS AND METHODS}

Prior to the commencement of the study, approval was obtained from the Ethical Committee of the Institution Review Board. Criteria for participant enrolment included female subjects between the age group of 18-45 years, diagnosed as having FM using the Revised Fibromyalgia criteria, 2016 and not undergoing anyother physiotherapeutic intervention. The exclusion criteria were pregnant/lactating women and subjects with associated co-morbidities. Over 220 females were screened from educational institutions in Belagavi, India for the study. Out of which, 33 women were diagnosed as having fibromyalgia as per the Revised Fibromyalgia Criteria, 2016 and 30 women were recruited for the study based on those willing to receive intervention for a duration of 7 days. The subjects were briefed about the nature of the study, their informed consent was taken and they were randomly allocated into two groups using the envelope method. The two groups consisted of yoga and strengthening exercises.

\section{INTERVENTION}

The Yoga group performed warm up for 5 minutes, 13 asanas (physical poses) to be maintained for a total of 20 minutes, followed by 5 minutes of pranayamas (breathing exercise) and 20 minutes of dhyaana (mindfulness meditation). Each asanawas maintained for 3 sets of 30 seconds for total of 1.5 minutes. The asanas were Parvatasana (mountain pose), Tadasana (mountain pose with sun arms), 
Veerbhadrasana (Warrior pose), Utkatasana (Chair pose), Adhomukhasavasana (Downward facing $\operatorname{dog}$ on chair pose), Bhujangasana (sphinx pose), Shalabhasana (Modified locust pose), Balasana (Child pose), Suptakapotasana (Supine pigeon pose), Natrajasana (Supine thoracic twist pose), Setubandhsarvangasana (bridge pose), Pavanmuktasana (Supine knee to chest pose) and Shavasana (Corpse pose). The pranayamas included practising Nadishodhana pranayama for 5 minutes and mindfulness meditation was practised after the pranayamas for 20 minutes with light classical music.

Strengthening exercises began with warm up for 5 minutes, followed by strengthening exercises for 40 minutes and cool down for 5 minutes. Strengthening exercises included shoulder flexors/extensors, abductors/adductors and elbow flexors/extensors and hip flexors/ extensors, knee flexors/extensors, ankle plantarlexors/dorsiflexors strengthening and core muscle strengthening. Strengthening for upper limb was done using dumbbell and for lower limb using weight cuff. The resistance to be offered for every muscle was calculated using $1 \mathrm{RM}$ and noted and progression of the exercise was done using 8-10-12-12 repetition format. Core muscle strengthening began with static contractions for pelvic and lumbar spine stabilisation followed by crunches and trunk extension exercises. Both the groups received treatment for 50 minutes per session.

\section{OUTCOME MEASURES}

Scores of Revised Fibromyalgia Impact Questionnaire (FIQR) were collected pre and post intervention. FIQR consists of three domains. The first domain enquires about the difficulty in performing activities, the second domain consists of questions about overall impact of fibromyalgia and third domain consists of questions about intensity of fibromyalgia symptoms over the last 7 days. The scores of each question in every domain were calculated, and the score of first domain was divided by 3 , score of second domain was divided by one and score of third domain was divided by 2 . The score thus obtained from each domain was then added together and the total score was obtained.

\section{RESULT}

The pre-test mean of FIQR was 28.90 in group A and 26.97 in group B. The post-test mean of FIQR was 10.30 in group $A$ and 14.53 in group B. Therefore, percentage change in group A was $64.36 \%$ and in group B was $46.11 \%$. (Table I, Figure 1)

Table I: Comparison of Group A and Group B with respect to Total FIQR scores at pre test and post test time points by independent $t$ test.

\begin{tabular}{|c|c|c|c|c|c|c|}
\hline \multirow[t]{2}{*}{ Groups } & \multicolumn{2}{|c|}{ Pretest } & \multicolumn{2}{|c|}{ Posttest } & \multicolumn{2}{|c|}{ Changes } \\
\hline & Mean & SD & Mean & SD & Mean & SD \\
\hline Group A & 59.11 & 15.20 & 19.07 & 7.88 & 40.04 & 10.71 \\
\hline Group B & 53.84 & 12.85 & 29.02 & 12.13 & 24.82 & 12.31 \\
\hline$\%$ of change in group $\mathrm{A}$ & & & & & \multicolumn{2}{|c|}{$67.73 \% \#, \mathrm{p}=0.0001 *$} \\
\hline$\%$ of change in group $\mathrm{B}$ & & & & & \multicolumn{2}{|c|}{$46.10 \% \#, p=0.0001^{*}$} \\
\hline t-value & \multicolumn{2}{|c|}{1.0260} & \multicolumn{2}{|c|}{-2.6632} & \multicolumn{2}{|c|}{3.6119} \\
\hline P-value & \multicolumn{2}{|c|}{0.3137} & \multicolumn{2}{|c|}{$0.0127 *$} & \multicolumn{2}{|c|}{$0.0012 *$} \\
\hline
\end{tabular}

$* \mathrm{p}<0.05$, \#applied dependent $\mathrm{t}$ test 


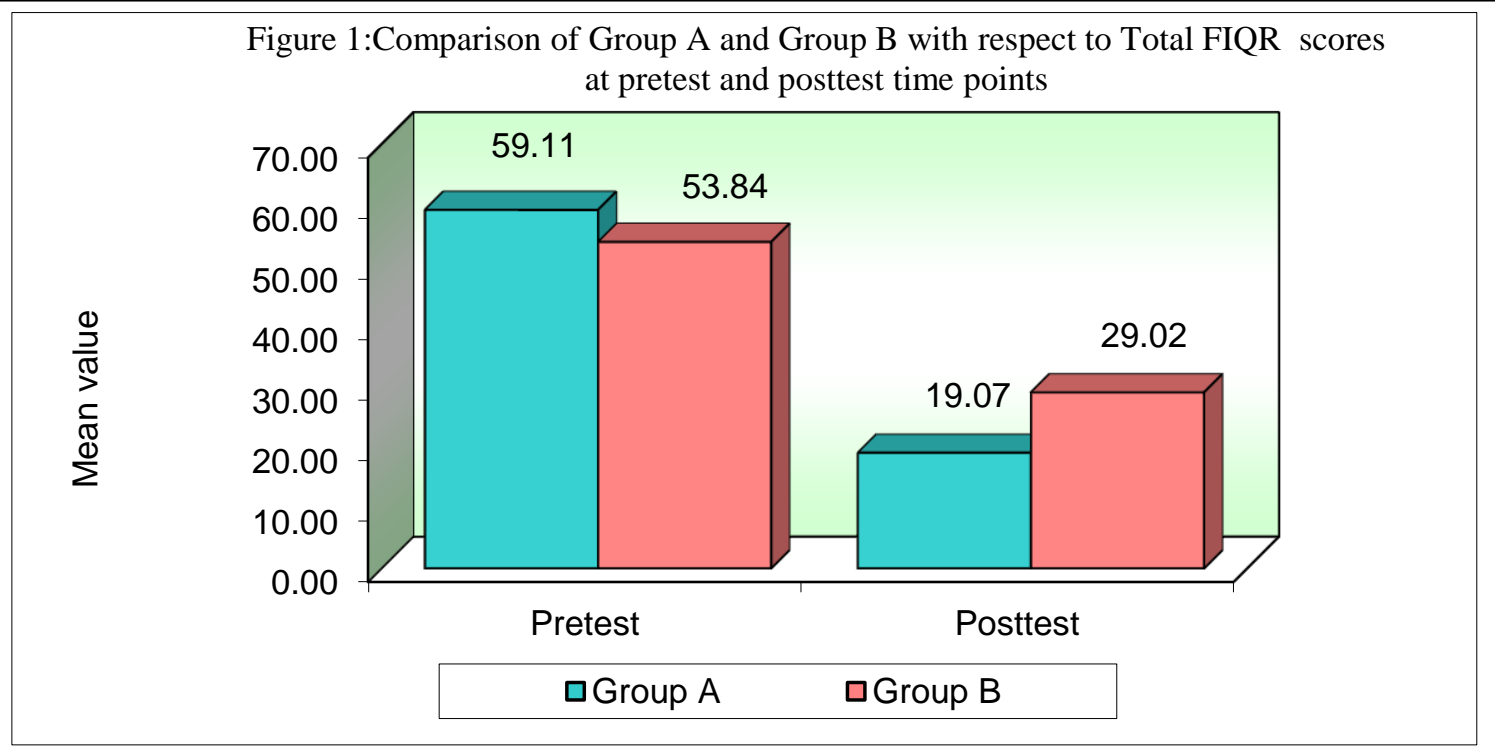

\section{DISCUSSION}

The present experimental study demonstrated that both the groups were beneficial, however, between the two groups; yoga was more effective than strengthening exercises to improve the symptoms of FM. Strengthening induces increase in maximum voluntary force from muscle fibres and area of muscle fibres which leads to increased motor unit firing pattern and hypertrophy of muscle, D. A. Jones et al (1986). ${ }^{(18)}$ Strengthening acts on the mechanoreceptors of joints and muscles, which get stimulated after strength training, inhibit the local nociceptors and activate the descending pain inhibitory pathways such that the sensory cortex identifies peripheral stimulus as less painful, causing reduction in pain. ${ }^{(18)}$ Another factor could be synthesis of endogenous opioids, which is stimulated post strength training, which may have alleviated pain in these subjects. ${ }^{(18)}$ Several studies have favoured the present study result wherein with strengthening exercises there was improvement in the symptoms of FM. Astudy was done by J. Derek Kingsley et al, where strengthening had demonstrated to show improved components of functionality like the amount of weight carried in tasks, decreased time to achieve tasks and no significant change in cardiovascular values measured by heart rate in the different tasks compared with the control group using
Fibromyalgia Impact Questionnaire and Continuous-Scale Physical Functional Performance (CSPFP) to assess the physical function. ${ }^{(19)}$ However, there were no significant changes in the upper body flexibility and balance. ${ }^{(19)}$ A study done by Daniel S Rooks et al described strength training activities assafe, feasible and beneficial to improve muscle strength, walking distance, functional status and severity of symptoms in FM. ${ }^{(20)}$ Kim Dupree Jones et al stated in their study that post strength training in females with FM improvement was seen in total myalgic score, number of tender points, VAS for pain, knee strength for extension and flexion, shoulder strength for internal and external rotation, hand to neck flexibility and hand to scapula flexibility, Beck Anxiety Inventory Questionnaire Score, Beck Depression Inventory Questionnaire Score, Quality of Life Questionnaire Score, Fibromyalgia Impact Questionnaire Score and Self-efficacy Scale Score. ${ }^{(21)}$

Yoga is comprised of 3 principles: pranayama (breathing techniques), asanas (posture) and dhyaana (meditation). ${ }^{(16,22)}$ Each of these has an effect on the neurobiological functioning. ${ }^{(22)}$ Pranayama controls the breath and ultimately, the mind, it invigorates the entire body - mind system. ${ }^{(23)}$ The respiratory and nervous systems are calmed and strengthened and all the cells receive the pranaor 
life force energy from the breathing. ${ }^{(23)}$ Breathing exercises influence Autonomic Nervous System, leading to variability in heart rate and cardiac vagal tone. ${ }^{(24)}$ Mind and emotions experience stillness. As the respireatory rates slow down, heart rate in relation becomes slower. ${ }^{(23)}$ This in turn affects the entire Circulatory System and reduces the load on the heart, allowing it to rejuvenate. The Sympathetic Nervous System receives the message that 'It is okay to relax!' and thus the Parasympathetic Nervous System initiates the relaxation response. ${ }^{(23)}$ This can be one of the vital reasons for reduction of the intensity of symptoms and reduction in the post intervention score of FIQR. Pushpendra Kumar conducted a study, wherein he established that asanas redirect physical action and behaviour and stimulate various glands, muscles and parts of the body related to emotional reactivity. Different state of mind can be activated or soothed through asanas. ${ }^{(25)}$ Asanas have been found to improve mood, depression, relieve stress and contribute to increase cortisol levels in the body. ${ }^{(26)}$ Cortisol is a hormone associated with improved self-esteem, hardiness, and stability of mind and lower levels of anxiety, depression, and emotional instability. ${ }^{(26)}$

Regular practice of meditation or Dhyaanais found to increase thickness of cortical regions of brain related to somatosensory, auditory, visual and interoceptive processing and may also slow down the age-related thinning of the frontal cortex. ${ }^{(27)}$ Thus influencing psychiatric, emotional activity and stress-related symptoms like anxiety, depression, chronic pain, immunity, high blood pressure, telomerase activity and cortisol level. ${ }^{(24,27)} \mathrm{A}$ study done byShamini Jain et al, found that meditation attempts to cultivate non-judgmental, moment to moment awareness to inner as well as outer stimuli. ${ }^{(28)}$ The development of this skill would result in the ability to shift and redirect attention to the present moment rather than thinking about past or future experience or otherwise distracting oneself from the present moment. ${ }^{(28)}$

Strength training only seems to act on the musculoskeletal system of the body, whereas Yoga also acts on different levels, involving various somatic and psychological subsystems, which maybe the reason for greater improvement seen in yoga group in this study. ${ }^{(24)}$

The limitations of this study are that long term effects of the interventions were not observed and the domain wise analysis of FIQR was not done.

\section{CONCLUSION}

The present study concludes that both Yoga and strengthening exercises are effective in the symptoms of fibromyalgia in women, however Yoga has greater effect than Strengthening exercises. Hence, FM subjects need to practise regular yoga to minimise the symptoms as much as possible.

\section{CONFLICT OFINTEREST- None}

\section{REFERENCES}

1. Wolfe F, Ross K, Anderson J, Russell IJ, Hebert L. The prevalence and characteristics of fibromyalgia in the general population. Arthritis \& Rheumatism. 1995 Jan 1;38(1):19-28.

2. Weir PT, Harlan GA, Nkoy FL, Jones SS, Hegmann KT, Gren LH, Lyon JL. The incidence of fibromyalgia and its associated comorbidities: a populationbased retrospective cohort study based on International Classification of Diseases, 9th Revision codes. JCR: Journal of Clinical Rheumatology. 2006 Jun 1;12(3):124-8.

3. Jones $\mathrm{KD}$, Gelbart $\mathrm{T}$, Whisenant $\mathrm{TC}$, Waalen J, Mondala TS, Iklé DN, Salomon DR, Bennett RM, Kurian SM. Genome-wide expression profiling in the peripheral blood of patients with fibromyalgia. Clinical and experimental 
rheumatology. 2016 May;34(2 Suppl 96):89.

4. Adler GK, Geenen R. Hypothalamicpituitary-adrenal and autonomic nervous system functioning in fibromyalgia. Rheumatic Disease Clinics of North America. 2005 Feb 28;31(1):187-202.

5. Paiva ES, Deodhar A, Jones KD, Bennett R. Impaired growth hormone secretion in fibromyalgia patients: evidence for augmented hypothalamic somatostatin tone. Arthritis \& Rheumatism. 2002 May 1;46(5):1344-50.

6. Bennett RM, Cook DM, Clark SR, Burckhardt CS, Campbell SM. Hypothalamic-pituitary-insulin-like growth factor-I axis dysfunction in patients with fibromyalgia. The Journal of rheumatology. 1997 Jul;24(7):1384-9.

7. Wolfe F, Smythe HA, Yunus MB, Bennett RM, Bombardier C, Goldenberg DL, Tugwell P, Campbell SM, Abeles M, Clark P, Fam AG. The American College of Rheumatology 1990 criteria for the classification of fibromyalgia. Arthritis \& Rheumatism. 1990 Feb 1;33(2):160-72

8. Wolfe F, Clauw DJ, Fitzcharles MA, Goldenberg DL, Katz RS, Mease P, Russell AS, Russell IJ, Winfield JB, Yunus MB. The American College of Rheumatology preliminary diagnostic criteria for fibromyalgia and measurement of symptom severity. Arthritis care\& research. 2010 May 1;62(5):600-10.

9. Wolfe F, Clauw DJ, Fitzcharles MA, Goldenberg DL, Häuser W, Katz RS, Mease P, Russell AS, Russell IJ, Winfield JB. Fibromyalgia criteria and severity scales for clinical and epidemiological studies: a modification of the ACR Preliminary Diagnostic Criteria for Fibromyalgia. The Journal of rheumatology. 2011 Jun 1;38(6): 1113-22.

10. Wolfe F, Clauw DJ, Fitzcharles MA, Goldenberg DL, Häuser W, Katz RL, Mease PJ, Russell AS, Russell IJ, Walitt B. 2016 Revisions to the 2010/2011 Fibromyalgia Diagnostic Criteria. InSeminars In Arthritis and Rheumatism 2016 Aug 30. WB Saunders.

11. Macfarlane GJ, Kronisch C, Dean LE, Atzeni F, Häuser W, Fluß E, Choy E, Kosek E, Amris K, Branco J, Dincer F. EULAR revised recommendations for the management of fibromyalgia. Annals of the Rheumatic Diseases. 2016 Jul 4:annrheumdis-2016.

12. Busch AJ, Barber KA, Overend TJ, Peloso PM, Schachter CL. Exercise for treating fibromyalgia syndrome. The Cochrane Library. 2007 Oct 17.

13. Mengshoel AM. Physiotherapy and fibromyalgia: A literature review. Advances in Physiotherapy. 1999 Jan 1;1(2):73-82.

14. Jones KD, Burckhardt CS, Clark SR, Bennett RM, Potempa KM. A randomized controlled trial of muscle strengthening versus flexibility training in fibromyalgia. The Journal of rheumatology. 2002 May 1;29(5):10418.

15. Kingsley JD, Panton LB, Toole T, Sirithienthad P, Mathis R, McMillan V. The effects of a 12-week strength-training program on strength and functionality in women with fibromyalgia. Archives of physical medicine and rehabilitation. 2005 Sep 30;86(9):1713-21.

16. Curtis K, Osadchuk A, Katz J. An eightweek yoga intervention is associated with improvements in pain, psychological functioning and mindfulness, and changes in cortisol levels in women with fibromyalgia. 
17. Carson JW, Carson KM, Jones KD, Bennett RM, Wright CL, Mist SD. A pilot randomized controlled trial of the Yoga of Awareness program in the management of fibromyalgia. PAIN®. $2010 \quad$ Nov 30;151(2):530-9.

18. Jones DA, Rutherford OM. Human muscle strength training: the effects of three different regimes and the nature of the resultant changes. Journal of Physiology. 1986 June 20

19. Kingsley JD, Panton LB, Toole T, Sirithienthad P, Mathis R, McMillan V. The effects of a 12-week strength-training program on strength and functionality in women with fibromyalgia. Archives of physical medicine and rehabilitation. 2005 Sep 30;86(9):1713-21.

20. Rooks DS, Silverman CB, Kantrowitz FG. The effects of progressive strength training and aerobic exercise on muscle strength and cardiovascular fitness in women with fibromyalgia: a pilot study. Arthritis Care \& Research. 2002 Feb 1;47(1):22-8.

21. Jones KD, Burckhardt CS, Clark SR, Bennett RM, Potempa KM. A randomized controlled trial of muscle strengthening versus flexibility training in fibromyalgia. The Journal of rheumatology. 2002 May 1;29(5):1041-8.

22. Carson JW, Carson KM, Jones KD, Lancaster L, Mist SD. Mindful Yoga Pilot Study Shows Modulation of Abnormal Pain Processing in Fibromyalgia Patients. International journal of yoga therapy. 2016;26(1):93-100.

23. Bennett B. Emotional yoga: How the body can heal the mind. Simon and Schuster; 2011 Nov 8.

24. Nespor K. Pain management and yoga. Int J Psychosom. 1991;38(1-4):76-81.

25. Kumar P. Effect of Yoga on Mental Health of Adolescents.

26. Woolery A, Myers H, Sternlieb B, Zeltzer L. A yoga intervention for young adults with elevated symptoms of depression. Alternative therapies in health and medicine. 2004 Mar 1;10(2):60.

27. Lazar SW, Kerr CE, Wasserman RH, Gray JR, Greve DN, Treadway MT, McGarvey M, Quinn BT, Dusek JA, Benson H, Rauch SL. Meditation experience is associated with increased cortical thickness. Neuroreport. 2005 Nov 28;16(17):1893.

28. Jain S, Shapiro SL, Swanick S, Roesch SC, Mills PJ, Bell I, Schwartz GE. A randomized controlled trial of mindfulness meditation versus relaxation training: effects on distress, positive states of mind, rumination, and distraction. Annals of behavioral medicine. 2007 Feb 1;33(1):1121. 